\title{
Asymptomatic Sertoli cell tumour diagnosed during azoospermia work-up
}

\author{
Hakan Ozturk $^{1}$, Musa Saracoglu ${ }^{1}$, Tarik Zengin ${ }^{1}$, Oya Nermin Sivrikoz ${ }^{2}$, Hüseyin Serhat Kerman ${ }^{1}$ \\ and Saban Adakan ${ }^{3}$
}

Asian Journal of Andrology (2013) 15, 845-846; doi:10.1038/aja.2013.101; published online 14 October 2013

Dear Editor,

Among the sex cord tumours, Sertoli cell tumours constitute $1 \%$ of all testicular tumours. The association between Sertoli cell tumours and azoospermia is not well defined, and the patient described in this letter is the second case reported in the literature.

Sex cord tumours account for approximately $4 \%$ of all testicular tumours. These tumours originate from Sertoli cells and usually occur in adults over 45 years old. ${ }^{1}$ Tumour diameter may range between 1 and $20 \mathrm{~cm}$. Based on the classification of the World Health Organization, Sertoli cell tumours are classified as sex cord/gonadostromal tumours, Sertoli cell tumours and malignant Sertoli cell tumours. ${ }^{1}$ The morphology of the Sertoli cells forming the tumours may be of the foetal, prepubertal, or adult type. A Sertoli cell tumour is macroscopically round, lobular and well circumscribed. Typical but difficult to observe, 'Charcot-Böttcher crystals' are located in the cytoplasm of the Sertoli cells. Mitosis may be present but is typically infrequent. ${ }^{2,3}$ Mitotic activity is not an absolute index of malignancy. Beyond classical Sertoli cell tumours, calcified big-cell Sertoli cell tumours and the sclerosing type of Sertoli cell tumour are very rare. ${ }^{2,3}$ Sertoli cell tumours immunohistochemically stain for vimentin, keratin, inhibin, calretinin and s-100 protein (Figure 1). The cells do not stain for plancental alkaline phosphatise alpha-fetoprotein, or human chorionic gonadotropin, which are important in distinguishing these tumours from germ cell tumours. Sertoli cell tumours are most frequently confused with Sertoli cell nodules, Leydig cell tumours and rete testis adenomas.

A 29-year-old man who was married and had not used contraception for 4 years presented in June 2006 because he wanted to have a child. Andrological investigations were performed upon finding azoospermia ( $\times 2$ and pellet) in the subject. Upon physical examination, a painless and well-circumscribed nodule that was $10 \mathrm{~mm}$ in diameter was found on the right testicle. Using colour Doppler ultrasound examination, a solid mass that was $11 \times 8 \mathrm{~mm}$ in size was discovered at the centre of his right testicle. Increased arterial perfusion was observed at the posterior of the well-circumscribed mass. The serum levels of alpha-fetoprotein, $\beta$-human chorionic gonadotropin and lactate dehydrogenase were all within the normal limits. The serum level of follicle-stimulating hormone was high, and the serum levels of luteinizing hormone, prolactin, testosterone and estriol were within the normal limits. Based on genetic examination, the karyotype was normal $(46, \mathrm{XY})$, and no microdeletion was observed on the $\mathrm{Y}$ chromosome. The patient, who had a presumed diagnosis of a testicular tumour, underwent radical orchiectomy. Tissues from healthy parts of the testicle were sent to the andrology laboratory, and the observed spermatozoa underwent cryopreservation. Histopathological examination revealed a nodular, grey-white lesion of $8 \mathrm{~mm}$ in diameter that was limited to the testicle and consistent with a classical Sertoli cell tumour without mitosis. Inhibin, vimentin and cytokeratin staining were positive in an immunohistochemical examination. No pregnancy was achieved with intracytoplasmic sperm injection applications using cryotesticular sperm extraction (TESE) in 2006 and 2007. In 2010, a twin pregnancy and twin live birth were achieved with intracytoplasmic sperm injection application using fresh TESE. The patient was tumour free in the 5-year follow-up period.

Sertoli cell tumours, in the category of sex cord stromal tumours, account for only $1 \%$ of all testicular tumours. In total, 170 cases have been reported in the literature. ${ }^{4}$ The first sign is usually a painless mass, and the serum levels of alpha-fetoprotein, $\beta$-human chorionic gonadotropin and lactate dehydrogenase are within the normal limits. As for all testicular tumours, the risk of developing a Sertoli cell tumour increases in patients with undescended testicles and those who have been operated on for this condition. ${ }^{5}$ Sertoli cell tumours are observed as nodular masses that are easily distinguished from testicular tissue during ultrasound examination. Although organ-sparing treatment is recommended in the form of partial orchiectomy, a significant proportion of these patients undergo radical orchiectomy. Immunohistochemical investigations facilitate the approach to the diagnosis. Malignant transformation occurs in approximately $10 \%$ of Sertoli cell tumours. Less than 50 cases have been reported in the literature. The malignancy criteria are as follows: a size of more than $5 \mathrm{~cm}$, pleomorphic nuclei with nucleoli, three or more mitoses per 10 magnification fields and vascular spread. ${ }^{1}$ Metastasis has been defined in malignant cases. Only $7 \%$ of all cases demonstrate metastasis during follow-up. Metastatic disease does not respond well to radio-chemotherapy, and survival is poor. ${ }^{6}$

Sertoli cell tumours may be associated with androgenic deficiency, Peutz-Jeghers syndrome and Carney's syndrome. ${ }^{6}$ None of these

${ }^{1}$ Department of Urology, Sifa University, Izmir 35240, Turkey; ${ }^{2}$ Department of Pathology, Sifa University, Izmir 35240, Turkey and ${ }^{3}$ Department of Obstetrics and Gynecology, Sifa University, Izmir 35240, Turkey 


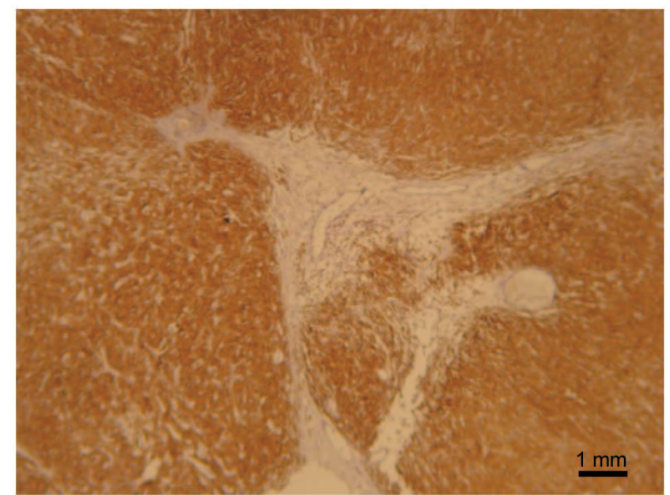

Figure 1 Staining of the tissue as immunohistochemical with 'inhibin', microscopic upsizing $(\times 40)$.

conditions was present in our case. The association between Sertoli cell tumours and azoospermia is not well defined in the literature. Our patient is the second subject having such a diagnosis. ${ }^{7}$ Infertility is among the risk factors for the development of testicular tumours. Tumours developing in patients with azoospermia are usually germinal tumours, but Sertoli cell tumours may also develop in rare cases, as reported here. Mancini et al. ${ }^{8}$ divided azoospermic patients undergoing TESE into two groups with or without Sertoli cell-only syndrome. The authors found the prevalence of testicular nodules and tumours to be higher in the patients with Sertoli cell-only syndrome and suggested that the patients be followed up in infertility clinics, as infertility should be examined in the presence of testicular nodules. ${ }^{8}$ Partial gr/gr deletion of the sub-locus of the azoospermia factor locus (AZF; Yq11), known as AZFc and with a well-known association with male infertility, is one of the genes predisposing an individual to testicular tumours that was defined as a consequence of candidate gene research. ${ }^{9}$ This deletion increases the risk of the development of a testicular tumour by approximately two- to threefold. Thus, gr/ gr deletion is an important risk factor. Neither genetic abnormality nor microdeletion was found in our case.
In conclusion, the risk of developing a testicular tumour increases in the presence of azoospermia. Investigations for testicular tumours should be performed during the assessment of infertile patients, and TESE should be scheduled given this condition. Furthermore, pathological examination seems to be mandatory, even though spermatozoa are found in the tissues obtained by TESE. The importance of this case is that the patient was the second subject in the literature in whom an association of azoospermia with a Sertoli cell tumour was observed.

\section{AUTHOR CONTRIBUTIONS}

HO, MS, TZ, HSK contemplated the manuscript. HO and MS carried out TESE surgical procedure to the case. SA carried out ICSI. ONS diagnosed pathological preparations of the case by immunohistochemical staining. HO drafted the manuscript. All authors reviewed and approved the final manuscript.

\section{COMPETING FINANCIAL INTERESTS}

All authors declare no competing financial interests.

1 Eble JN, Sauter G, Ebstein JI, Sesterhenn IA, editors. World Health Organization Classification of Tumors. Pathology and Genetics of Tumors of the Urinary system and Male Genital Organs. Lyon: IARC Press; 2004. p217-78.

2 Young RH. Sex-cord tumors of the testis. Pathol Case Rev 2005; 10: 193-205.

3 Young RH, Koelliker DD, Scully RE. Sertoli cell tumors of the testis, not otherwise specified: a clinicopathologic analysis of 60 cases. Am J Surg Pathol 1998; 22: 709-21.

4 Gómez García I, Romero Molina M, López-García Moreno A, Buendía González E, Rubio Hidalgo $E$ et al. Sertoli cell tumor, a rare testicular tumor, our experience and review of the literature. Arch Esp Urol 2010; 63: 392-5.

5 Mancini M, Carmignani L, Gazzano G, Sagone P, Gadda F et al. High prevalence of testicular cancer in azoospermic men without spermatogenesis. Hum Reprod 2007; 22: $1042-6$.

6 Albers P, Albrecht W, Algaba F, Bokemeyer C, Cohn-Cedermark G et al. Guidelines on testicular cancer. Eur Urol 2005; 48: 885-94.

7 Vallangeon BD, Eble JN, Ulbright TM. Macroscopic sertoli cell nodule: a study of 6 cases that presented as testicular masses. Am J Surg Pathol 2010; 34: 1874-80.

8 Mancini M, Carmignani L, Gazzano G, Sagone P, Gadda F et al. High prevalence of testicular cancer in azoospermic men without spermatogenesis. Hum Reprod 2007; 22: $1042-6$.

9 Nathanson KL, Kanetsky PA, Hawes R, Vaughn DJ, Letrero R et al. The Y deletion gr/gr and susceptibility to testicular germ cell tumor. Am J Hum Genet 2005; 77: 103443. 